\title{
Clinical, haemodynamic, and pharmacological effects of withdrawal and reintroduction of digoxin in patients with heart failure in sinus rhythm after long
}

\section{term treatment}

\author{
S E PUGH, N J WHITE, J K ARONSON, D G GRAHAME-SMITH, \\ J G BLOOMFIELD
}

From the Medical Research Council Unit and University Department of Clinical Pharmacology, Radcliffe Infirmary, Oxford

SUMMARY A randomised, double blind, placebo controlled, crossover study of digoxin withdrawal and reintroduction was carried out over two periods of eight weeks each after long term treatment. Forty four patients with stable heart failure in sinus rhythm and plasma digoxin concentrations over $0.8 \mathrm{ng} / \mathrm{ml}$ were studied. Their progress was assessed by clinical criteria, by haemodynamic measurements (systolic time intervals and echocardiography), and by pharmacological measurements of erythrocytic sodium pump numbers and activity. After withdrawal of digoxin clinical deterioration occurred in only $25 \%$ of the patients. Furthermore, in only $9 \%$ of cases was digoxin reintroduction thought to be necessary. There was deterioration in only $11 \%$ of the patients during digoxin treatment. Deterioration during digoxin withdrawal was accompanied by changes in systolic time intervals, but similar, albeit smaller changes in systolic time intervals also occurred in patients with no deterioration. Deterioration was accompanied by changes in the pharmacological effects of digoxin on the erythrocytes, consistent with a loss of effect, and these changes did not occur in those who did not deteriorate. The occurrence of deterioration could not be predicted by any clinical, haemodynamic, or pharmacological measurements made before withdrawal.

When William Withering first used digitalis in the successful treatment of dropsy over 200 years ago, his practice was to give it for short periods of time. ${ }^{1}$ This century the usefulness of digitalis as a positive inotropic drug in the treatment of heart failure was rediscovered, but it has been modern practice to use it for indefinite periods.

In recent years, however, the practice of continuing treatment indefinitely with digitalis in heart failure in sinus rhythm has been questioned. For example, in several studies it has been shown that most patients do not deteriorate clinically when digitalis is withdrawn after long term treatment. ${ }^{23}$ Furthermore, some have shown that systolic time

Author for correspondence: Dr J K Aronson, MRC Clinical Pharmacology Unit, University Department of Clinical Pharmacology, Radcliffe Infirmary, Woodstock Road, Oxford OX2 6HE.

Accepted for publication 20 January 1989 intervals, and other measures of haemodynamic function, do not change in patients whose clinical state does not deteriorate after withdrawal, 46 although this finding has not been confirmed by others. ${ }^{7-10}$ In addition, we and others have shown that the cellular pharmacological effects of digoxin, demonstrable in the erythrocytes of patients on short term digoxin treatment, are not found in patients on long term treatment, suggesting tolerance to the pharmacological effects of digoxin. ${ }^{11} 12$

We decided, therefore, to carry out a randomised double blind, placebo controlled, crossover study of the effects of withdrawal and reintroduction of digoxin after long term treatment for heart failure in sinus rhythm, investigating simultaneously a range of different measures of the effects of digoxin clinically, haemodynamically, and pharmacologically. Our purposes were to determine the relations among these different levels of effect of digoxin (fig 1) and whether any of these measurements could be used to 


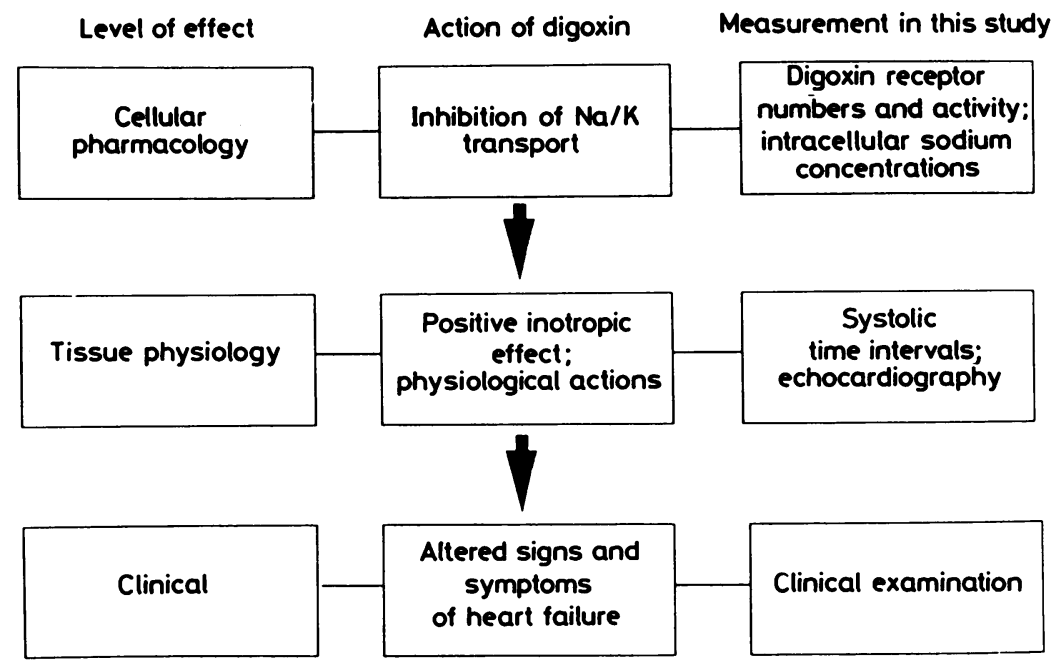

Fig 1 Different levels at which a drug may act in producing its therapeutic effect are shown on the left. A pharmacological effect at a cellular level is translated into a physiological effect, which in turn results in a clinical effect. The corresponding pharmacological, physiological (haemodynamic), and clinical effects of digoxin are shown in the centre column. The corresponding methods used in this study to investigate each of these levels of the action of digoxin are shown on the right.

predict the clinical outcome after the withdrawal of digoxin.

The study was given the approval of the local ethics committee.

\section{Patients and methods}

\section{PATIENTS}

We studied 44 patients, all of whom fulfilled the following criteria: (a) digitalised for heart failure in sinus rhythm; (b) taking digoxin (Lanoxin, Wellcome) for at least three months; (c) no clinical evidence of digitalis toxicity; (d) steady state plasma digoxin concentrations (at least six hours after the previous dose $) \geqslant 0.8 \mathrm{ng} / \mathrm{ml}(1.0 \mathrm{nmol} / \mathrm{l})$ and $\leqslant 2.0 \mathrm{ng} /$ $\mathrm{ml}(2 \cdot 6 \mathrm{nmol} / \mathrm{l})$.

Table 1 shows the patients' ages, sex distribution, causes of heart failure, duration of treatment with digoxin, and other drug treatments.

Criteria for exclusion were: (a) atrial fibrillation; (b) plasma digoxin concentration $<0.8 \mathrm{ng} / \mathrm{ml}$ or $>2.0 \mathrm{ng} / \mathrm{ml}$; (c) clinical evidence of fluid retention; (d) recent acute myocardial infarction ( $<3$ months before).

Table 1 Ages, sex distribution, causes of heart failure, duration of digoxin treatment, and other drug treatments at the start of the study

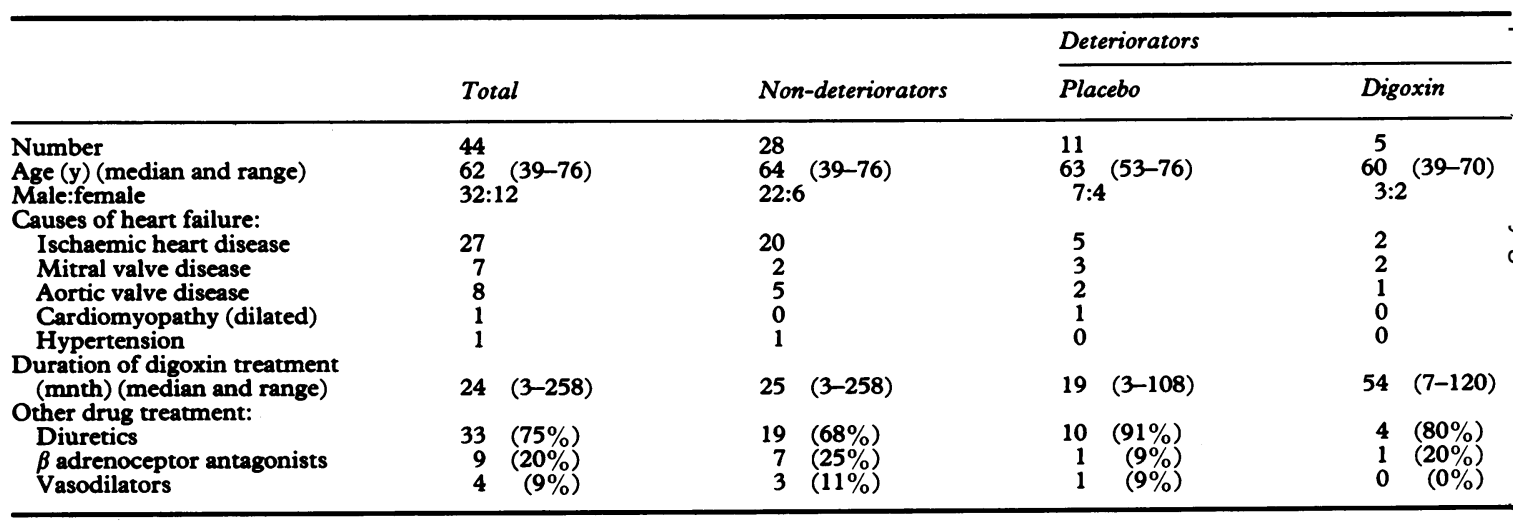


There were no exclusions based on other drug treatment, and wherever possible other drugs were continued in unchanging dosages throughout the study. Dosages of diuretics were increased during periods of deterioration when indicated (see Results).

\section{DESIGN OF THE STUDY}

Figure 2 shows the study design. After the initial assessment the patients were randomised to treatment with either their usual dosage of digoxin (Lanoxin) or to an equal number of matched placebo tablets. After eight weeks of continuous treatment (period 1) the alternative treatment was given and continued for a further eight weeks (period 2). All the patients were then given digoxin again for a final eight weeks (period 3 ). We have designated those patients who were randomised to placebo first as group 1 and those who were randomised to digoxin first as group 2.

When patients switched from placebo to digoxin treatment they were given three times the usual dose of digoxin on the first day only, as a loading dose. When they switched from digoxin to placebo extra placebo tablets were given to mimic a loading dose. Patients who "switched" from digoxin in period 2 to digoxin in period 3 were given their normal dose of digoxin on the first day of period 3 plus extra placebo tablets to mimic a loading dose. The issue of the tablets was controlled by the members of the phar- macy in the John Radcliffe Hospital, and the principal clinical investigators (SEP and NJW) were at all times blind to the order of the treatments. Clinical assessment was carried out both before randomisation and at weeks $1,2,4,6$, and 8 during each treatment period (fig 2). At the initial visit and at the first and eighth weeks of each treatment period (bold arrows in fig 2) the following investigations were made: full clinical assessment (history and examination); exercise test; measurement of systolic time intervals; echocardiography; blood tests (plasma digoxin concentration, erythrocyte cation transport receptor numbers and activity, and intra-erythrocytic sodium concentration). At the second, fourth, and sixth weeks of each visit (light arrows in fig 2) an interim assessment was made as follows: full clinical assessment; systolic time intervals; plasma digoxin concentration.

In the case of patients whose clinical condition deteriorated during the study a decision was made either to initiate or change diuretic treatment or to withdraw the patient from the study. One of us (JKA), who was blind to the order of treatments, was responsible for assessing what to do at times of apparent clinical deterioration, and for communicating between the blinded and non-blinded investigators, breaking the code as necessary. One of us (DGG-S) was not blind to the treatment order. He monitored the study and ensured that the dosages of

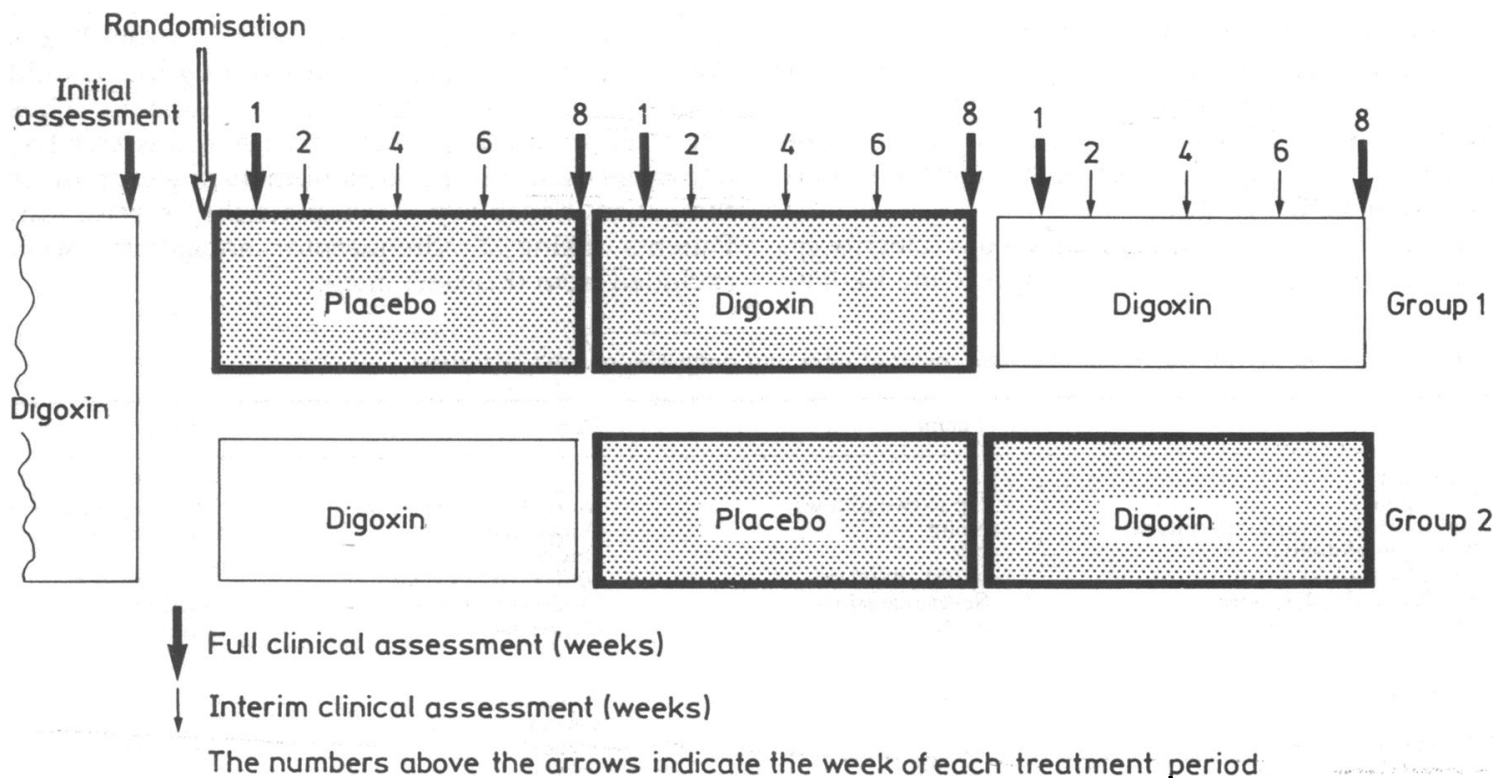

Fig 2 Treatment randomisation during the study. The stippled boxes show the observation periods that were the subject of statistical analysis. For statistical comparisons the data from the two placebo periods were combined, as were the data from the two digoxin periods immediately after placebo. 
digoxin were adequate to produce the desired plasma concentrations (measured by radioimmunoassay (JGB)).

\section{CLINICAL ASSESSMENT}

Each patient's clinical status was assessed on the basis of the presence or absence of the signs and symptoms listed in table 2 , and scored as shown there. The total clinical score ranged from 12 (normal) to a maximum of 35 (6-19 for symptoms and 616 for signs). Clinical deterioration was defined as a consistent increase in total score of at least two points, one of which had to be attributable to a worsening sign.

\section{HAEMODYNAMIC INVESTIGATIONS}

Systolic time intervals were recorded by a Schwarzer C3000 multichannel recorder at a paper speed of 100 $\mathrm{mm} / \mathrm{s}$ with (a) a phonocardiograph to pick up the initial high frequency component of the second heart sound at the point on the chest where the second sound was loudest, $(b)$ a pressure transducer held over the right carotid artery, and (c) the lead of the conventional electrocardiogram that most clearly showed the onset of the QRS component (usually lead II).

Measurements of systolic time intervals were taken under the same conditions throughout the study, at the same time of day, with patients lying at an angle of $45^{\circ}$, and after they had rested for at least 15 minutes. We calculated the following intervals as the means of ten consecutive beats and corrected for heart rate using the method of Weissler et $a l^{13}$ : the total electromechanical systole $\left(\mathrm{QS}_{2} \mathrm{I}\right)$, the left ventricular ejection time (LVETI), the pre-ejection period (PEPI) (all corrected for heart rate), and the ratio of uncorrected PEP/LVET.

Echocardiography with simultaneous electrocardiography was performed on a Smith Kline Ekoline

20 ultrasonoscope, with a sound transducer of $\stackrel{\frac{1}{\Phi}}{\Phi}$ frequency $2 \cdot 25 \mathrm{MHz}$, and printout via a Cambridge $\bar{c}$ recorder at a paper speed of $100 \mathrm{~mm} / \mathrm{s}$. Left ventricular $M$ mode recordings were obtained with consistent echoes from the interventricular septum 0 and posterior endocardium at the level of the tips of $\frac{}{0}$. the mitral valve leaflets. The position of the patient $\frac{\bar{s}}{\vec{s}}$ on the couch and of the transducer on the chest wall $\Phi$ were recorded on the first occasion, and subsequent $\nRightarrow$ measurements were made in the same positions at the same time of day. The left ventricular internal diameter was measured in diastole $\left(\right.$ LVID $\left._{\mathrm{d}}\right)$ at the $\overrightarrow{\vec{\omega}}$ time of the peak of the $R$ wave of the simultaneous $\stackrel{\sigma}{\sigma}$ electrocardiogram and in systole ( LVID $_{2}$ ) when the diameter was at a minimum. The dimensions were $\sigma$ calculated as the means of six consecutive beats. $\vec{\sigma}$ Fractional shortening and mean velocity of circum- in ferential fibre shortening (VCF) were calculated as $c$ follows:

$$
\begin{gathered}
\text { Fractional shortening }(\%)=\frac{\left(\text { LVID }_{d}-\text { LVID }_{s}\right) \times 100}{\text { LVID }_{d}} \\
\text { VCF }(\text { circ/s })=\frac{\text { VVID }_{d}-\text { LVID }_{s}}{\text { LVID }_{d} \times \text { LVET }}
\end{gathered}
$$

$A$ trial of exercise tolerance was performed in each patient before randomisation, on a treadmill with simultaneous electrocardiographic recording of resting and peak heart rates. A level of exercise at which the patient became dyspnoeic at or before 10 minutes was determined, and the rate of the treadmill was then reduced to the point at which the patient could just exercise for 10 minutes without dyspnoea. Thus any deterioration in exercise capacity was assessed by either the occurrence of dyspnoea during exercise or the patient's inability to complete the exercise test. Patients taking $\beta$ adrenoceptor antagonists were excluded from this assessment.

\begin{tabular}{|c|c|c|c|}
\hline & 1 point & 2 points & 3 points \\
\hline $\begin{array}{l}\text { Symptoms: } \\
\text { Orthopnoea } \\
\text { Paroxysmal nocturnal dyspnoea } \\
\text { Stairs (no of flights) } \\
\text { Distance walked } \\
\text { NYHA grade (dyspnoea) } \\
\text { Palpitation }\end{array}$ & $\begin{array}{l}\text { Up to two pillows } \\
\text { None } \\
>2 \\
>100 \text { yd }(90 \mathrm{~m}) \\
\text { Severe exertion } \\
\text { None }\end{array}$ & $\begin{array}{l}\text { More than three pillows } \\
\text { Occasional } \\
\text { One or two } \\
50-100 \text { yd }(45-90 \mathrm{~m}) \\
\text { Moderate exertion } \\
\text { Occasional }\end{array}$ & $\begin{array}{l}\text { Sleeping upright } \\
\text { Every night } \\
<1 \\
<50 \text { yd }(45 \mathrm{~m}) \\
\text { Mild exertion } \\
\text { Every day }\end{array}$ \\
\hline $\begin{array}{l}\text { Signs: } \\
\text { Third heart sound } \\
\text { Jugular venous pressure } \\
\text { Peripheral oedema } \\
\text { Tender hepatomegaly } \\
\text { Pulmonary oedema } \\
\text { Heart rhythm }\end{array}$ & $\begin{array}{l}\text { Absent } \\
0-2 \text { cm } \\
\text { Absent } \\
\text { Absent } \\
\text { Absent } \\
\text { Sinus }\end{array}$ & $\begin{array}{l}\text { Present } \\
2-6 \mathrm{~cm} \\
\text { To ankles } \\
\text { Present } \\
\text { Basal crackles }\end{array}$ & $\begin{array}{l}>6 \mathrm{~cm} \\
\text { Above ankles } \\
\text { Extensive crackles } \\
\text { Atrial fibrillation }\end{array}$ \\
\hline
\end{tabular}

Table 2 Scoring system for the clinical assessment of signs and symptoms of cardiac failure

NYHA, New York Heart Association. 
PHARMACOLOGICAL MEASUREMENTS

The specific binding of $\left[{ }^{3} \mathrm{H}\right]$-digoxin to the membranes of intact erythrocytes, a measure of the number of membrane bound sodium, potassiumadenosine triphosphatase $\left(\mathrm{Na}^{+}, \mathrm{K}^{+}-\mathrm{ATPase}\right.$; sodium/potassium pump) sites, and the rate of influx of rubidium-86 into intact erythrocytes were measured as previously described. ${ }^{14} 15$ Intraerythrocytic sodium concentrations were measured by atomic absorption spectrophotometry after the cells had been washed three times in isotonic magnesium chloride.

\section{STATISTICAL ANALYSIS}

Statistical comparisons were made by the following tests where appropriate: $\chi^{2}$ test; Wilcoxon's rank sum test; Student's paired or unpaired one-tailed or twotailed $t$ tests; one way analysis of variance with Tukey's test for individual differences.

\section{Results}

The design of the study (fig 2) allowed us to analyse both the effects of withdrawing digoxin (by combin- both the effects of withdrawing digoxin (by combining the placebo data from groups 1 and 2) and the effects of reintroducing digoxin (by analysing the digoxin data immediately after placebo treatment in groups 1 and 2 combined). This is illustrated in fig 2 , in which the treatment periods that we analysed are shown in the stippled boxes. There were no statistically significant differences in any of our methods of assessment between groups 1 and 2 during any of the corresponding treatment periods-for example, the measurements made immediately before the introduction of placebo were the same in group 1 as in group 2.

\section{ENTRY ASSESSMENT}

Table 3 shows the values at entry of the various measurements we made. There were no differences in any of these measurements when we compared those patients who subsequently deteriorated clinically with those who did not. In addition, there were no differences among the groups in terms of other drug treatments before the study (table 1), although the numbers of patients taking $\beta$ adrenoceptor

Table 3 Clinical, haemodynamic, pharmacological, and biochemical measurements at entry into the study (median (range) or mean (SD))

\begin{tabular}{|c|c|c|c|c|c|c|c|c|}
\hline \multirow{2}{*}{ Clinical score: } & \multirow{2}{*}{\multicolumn{2}{|c|}{$\begin{array}{l}\text { Total } \\
(n=44)\end{array}$}} & \multirow{2}{*}{\multicolumn{2}{|c|}{$\begin{array}{l}\text { Non-deteriorators } \\
(n=28)\end{array}$}} & \multicolumn{4}{|c|}{ Deteriorators } \\
\hline & & & & & $\begin{array}{l}\text { Placebo } \\
(n=11\end{array}$ & & $\begin{array}{l}\text { Digoxin } \\
(n=5)\end{array}$ & \\
\hline $\begin{array}{l}\text { Symptoms } \\
\text { Signs } \\
\text { Total score }\end{array}$ & $\begin{array}{r}8 \\
6 \\
15\end{array}$ & $\begin{array}{l}(6-12) \\
(6-12) \\
(12-24)\end{array}$ & $\begin{array}{r}8 \\
6 \\
14\end{array}$ & $\begin{array}{l}(6-12) \\
(6-9) \\
(12-19)\end{array}$ & $\begin{array}{r}9 \\
7 \\
15\end{array}$ & $\begin{array}{l}(6-11) \\
(6-12) \\
(13-23)\end{array}$ & $\begin{array}{r}8 \\
7 \\
14\end{array}$ & $\begin{array}{l}(6-8) \\
(6-9) \\
(13-17)\end{array}$ \\
\hline $\begin{array}{l}\text { Blood pressure }(\mathrm{mm} \mathrm{Hg}) \text { : } \\
\text { Systolic } \\
\text { Diastolic }\end{array}$ & $\begin{array}{r}135 \\
81\end{array}$ & $\begin{array}{l}(18) \\
(10)\end{array}$ & $\begin{array}{r}139 \\
80\end{array}$ & $\begin{array}{l}(19) \\
(10)\end{array}$ & $\begin{array}{r}132 \\
82\end{array}$ & $\begin{array}{l}(12) \\
(10)\end{array}$ & $\begin{array}{r}132 \\
84\end{array}$ & $\begin{array}{l}(21) \\
(9)\end{array}$ \\
\hline $\begin{array}{l}\text { Exercise heart rates (beats/min): } \\
\text { Resting } \\
\text { At peak exercise } \\
\text { Cardiothoracic ratio (\%) } \\
\text { Plasma biochemistry: }\end{array}$ & $\begin{array}{r}75 \\
108 \\
52\end{array}$ & $\begin{array}{l}(12) \\
(16) \\
(40-67)\end{array}$ & $\begin{array}{r}75 \\
107 \\
54\end{array}$ & $\begin{array}{l}(14) \\
(13) \\
(40-61)\end{array}$ & $\begin{array}{r}69 \\
108 \\
53\end{array}$ & $\begin{array}{l}(8) \\
(20) \\
(44-57)\end{array}$ & $\begin{array}{r}73 \\
116 \\
52\end{array}$ & $\begin{array}{l}(22) \\
(15) \\
(48-67)\end{array}$ \\
\hline $\begin{array}{l}\text { Sodium }(\mathrm{mmol} / \mathrm{l}) \\
\text { Potassium }(\mathrm{mmol} / \mathrm{l}) \\
\text { Urea }(\mathrm{mmol} / \mathrm{l}) \\
\text { Creatinine }(\mu \mathrm{mol} / \mathrm{l})\end{array}$ & $\begin{array}{c}140 \\
4 \cdot 2 \\
7 \cdot 4 \\
111\end{array}$ & $\begin{array}{l}(3 \cdot 1) \\
(0 \cdot 5) \\
(2 \cdot 0) \\
(48)\end{array}$ & $\begin{array}{r}140 \\
4 \cdot 2 \\
7 \cdot 3 \\
112\end{array}$ & $\begin{array}{l}(3 \cdot 5) \\
(0 \cdot 4) \\
(2 \cdot 2) \\
(59)\end{array}$ & $\begin{array}{r}141 \\
4 \cdot 0 \\
7 \cdot 5 \\
108\end{array}$ & $\begin{array}{l}(2 \cdot 1) \\
(0 \cdot 4) \\
(1 \cdot 4) \\
(19)\end{array}$ & $\begin{array}{r}134 \\
4 \cdot 5 \\
7 \cdot 7 \\
110\end{array}$ & $\begin{array}{l}(2 \cdot 0) \\
(0 \cdot 7) \\
(2 \cdot 1) \\
(22)\end{array}$ \\
\hline $\begin{array}{l}\text { Erythrocytic measurements: } \\
\left.\text { [ }{ }^{3} \mathrm{H}\right] \text {-digoxin binding (pg/0.5 ml } \\
\text { cells) } \\
\text { Rubidium-86 influx (pmol/1//h) } \\
\text { Intracellular sodium (mmol/1) }\end{array}$ & $\begin{array}{c}2544 \\
1 \cdot 90 \\
7 \cdot 1\end{array}$ & $\begin{array}{l}(878) \\
(0.47) \\
(1.9)\end{array}$ & $\begin{array}{c}2460 \\
1.96 \\
7 \cdot 1\end{array}$ & $\begin{array}{l}(685) \\
(0 \cdot 49) \\
(1 \cdot 6)\end{array}$ & $\begin{array}{c}2876 \\
1.87 \\
7 \cdot 3\end{array}$ & $\begin{array}{l}(1257) \\
(0 \cdot 48) \\
(2 \cdot 7)\end{array}$ & $\begin{array}{r}2168 \\
1.59 \\
6.8\end{array}$ & $\begin{array}{l}(746) \\
(0.22) \\
(1 \cdot 5)\end{array}$ \\
\hline $\begin{array}{l}\text { Systolic time intervals (ms): } \\
\text { QS } \\
\text { LVETI } \\
\text { PEPI } \\
\text { PEP/LVET } \\
\text { Echocardiography: } \\
\text { LVID }_{\text {(cm) }} \\
\text { LVID (cm) } \\
\text { Fractional shortening (\%) } \\
\text { VCF (circ/s) }\end{array}$ & $\begin{array}{c}531 \\
392 \\
137 \\
0.39 \\
\mathbf{n}=33 \\
5 \cdot 6 \\
4 \cdot 1 \\
27 \cdot 6 \\
0.88\end{array}$ & $\begin{array}{l}(27) \\
(27) \\
(26) \\
(0 \cdot 121) \\
(1 \cdot 3) \\
(1 \cdot 1) \\
(7 \cdot 9) \\
(0 \cdot 28)\end{array}$ & $\begin{array}{c}530 \\
394 \\
136 \\
0.38 \\
\mathbf{n}=21 \\
5 \cdot 4 \\
3.9 \\
27 \cdot 4 \\
0.94\end{array}$ & $\begin{array}{l}(21) \\
(21) \\
(21) \\
(0 \cdot 087) \\
(1 \cdot 1) \\
(0 \cdot 9) \\
(5 \cdot 4) \\
(0 \cdot 22)\end{array}$ & $\begin{array}{r}536 \\
387 \\
143 \\
0.45 \\
\mathrm{n}=10 \\
6 \cdot 1 \\
4.5 \\
26.9 \\
0.74\end{array}$ & $\begin{array}{l}(33) \\
(33) \\
(43) \\
1(0 \cdot 186) \\
(1 \cdot 5) \\
(1 \cdot 6) \\
(12 \cdot 2) \\
(0 \cdot 36)\end{array}$ & $\begin{array}{c}529 \\
403 \\
125 \\
0.539 \\
\mathrm{n}=2 \\
4.8 \\
3.2 \\
33.7 \\
1.04\end{array}$ & $\begin{array}{l}(16) \\
(32) \\
(20) \\
(0 \cdot 140) \\
(0 \cdot 1) \\
(0 \cdot 1) \\
(2 \cdot 5) \\
(0 \cdot 11)\end{array}$ \\
\hline
\end{tabular}

$\mathrm{QS}_{2} \mathrm{I}$, total electromechanical systole corrected for heart rate; LVETI, left ventricular ejection time corrected for heart rate; PEPI, pre-ejection period corrected for heart rate; VVID $_{\mathrm{d}}$ and $\mathrm{LVID}$, left ventricular internal diameters measured in diastole (d) or systole (s); VCF, velocity of circumferential fibre shortening. 
antagonists were too small to detect what may have been a true difference between the groups $(9 \%$ in placebo deteriorators, $20-25 \%$ in the other groups).

\section{CLINICAL DETERIORATION DURING THE STUDY}

During the study $28(64 \%)$ of the 44 patients showed no evidence of clinical deterioration on clinical assessment or on exercise testing. Of the other 16,11 (25\% of the total) deteriorated during the placebo period (increases in scores of 2-9 points, median 3), and five $(11 \%)$ patients deteriorated while taking digoxin (increases in scores of 2-4 points, median 3). Of the 11 who deteriorated while taking placebo, heart failure became worse in nine and two went into atrial fibrillation (both also with worsening heart failure). Of the five who deteriorated while taking digoxin, three developed worsening heart failure and two went into atrial fibrillation, but without heart failure. Among those who deteriorated, four patients had to be withdrawn from the study; of these, two deteriorated while taking placebo (one heart failure, one atrial fibrillation) and two deteriorated while taking digoxin (one heart failure, one atrial fibrillation). Worsening of heart failure while on placebo in those patients who were not withdrawn from the study was treated by increasing doses of diuretics, with a successful outcome in all but two cases, in whom heart failure resolved only on reintroduction of digoxin. In two patients worsening of heart failure in sinus rhythm while on digoxin was successfully treated with increased dosages of diuretics.

Table 4 shows the occurrence of deterioration in terms of the numbers of treatment periods during which deterioration did or did not occur. There were significantly more occasions on which deterioration occurred during placebo periods than during digoxin periods, both when the patients who developed atrial fibrillation are included $(p<0.04)$ and when they are not $(p=0.02)$.

\section{SYSTOLIC TIME INTERVALS}

Figure 3 shows the systolic time intervals measured at five different times: (1) immediately before the withdrawal of digoxin; (2 and 3 ) after placebo

Table 4 Clinical deterioration during the study, analysed by treatment period

\begin{tabular}{|c|c|c|}
\hline & \multicolumn{2}{|c|}{ Number of 8 week periods: } \\
\hline & $\begin{array}{l}\text { With } \\
\text { deterioration }\end{array}$ & $\begin{array}{l}\text { Without } \\
\text { deterioration }\end{array}$ \\
\hline $\begin{array}{l}\text { Digoxin treatment periods } \\
\text { Placebo treatment periods }\end{array}$ & $\begin{aligned} 5 & (3) \\
13 & (11) \\
& \text { p }<0.04\end{aligned}$ & $\begin{array}{l}37 \quad(37) \\
29 \quad(29) \\
0.02)\end{array}$ \\
\hline
\end{tabular}

The figures in parentheses are those when patients who developed atrial fibrillation are excluded. treatment for one week and eight weeks respectively $;$ (4 and 5) after the reintroduction of digoxin for one? week and eight weeks respectively.

The data were subdivided to compare those who $\overrightarrow{=}$ deteriorated during a placebo period with those whot did not deteriorate at all. In addition, the systolic time intervals at the time of deterioration are shownos. for those who deteriorated while they were taking placebo. There were too few data to allow con- 0 clusions about the changes in systolic time intervals ${ }^{\infty}$ in patients who deteriorated while taking digoxin. $\vec{\circ}$

In those who deteriorated during withdrawal of digoxin there was a significant increase in tota $\omega_{\infty}^{\infty}$ electromechanical systole $\left(\mathrm{QS}_{2} \mathrm{I}\right)$ after withdrawa $\bar{L}$ and a decrease after reintroduction. These changes in $\mathrm{QS}_{2} \mathrm{I}$ were attributable to similar changes in the pre-ejection period (PEPI), and there were no significante changes in the left ventricular ejection time (LVETI)
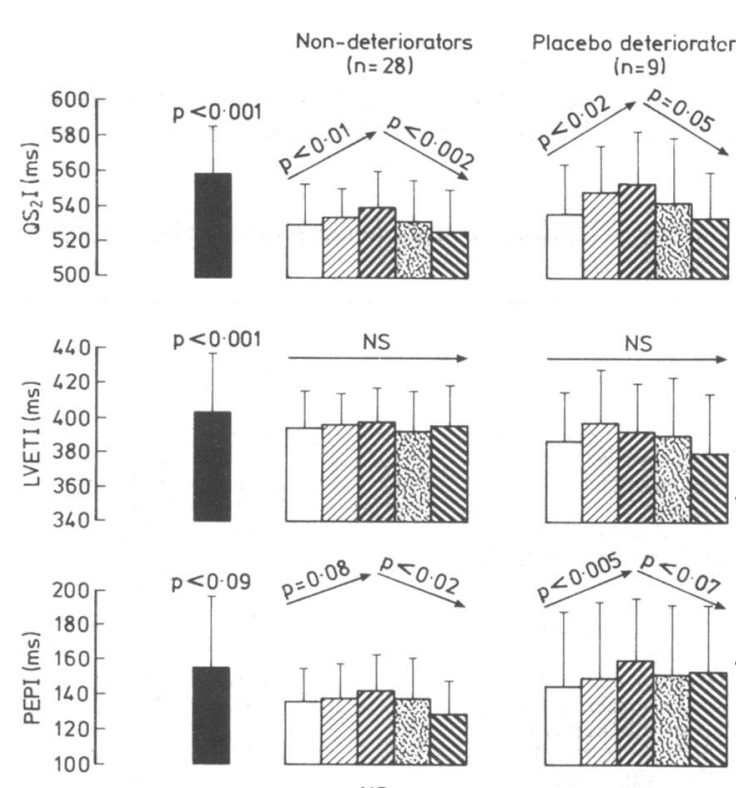

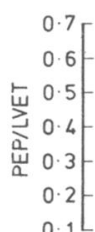
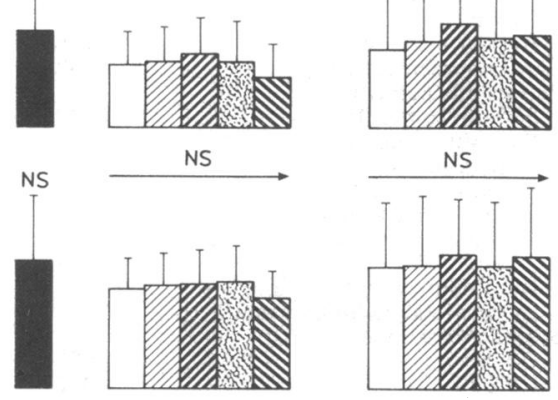

Fig 3 Systolic time intervals at different times of the study

- At time of deterioration during placebo

$\square$ Immediately before withdrawal of digoxin

After placebo treatment for one week

After placebo treatment for eight weeks

- After digoxin reintroduction for one week

After digoxin reintroduction for eight weeks

The same key is used in figs 4 and 5. 
or the ratio of PEP:LVET. Similar changes, but of smaller magnitude, were seen in patients who did not deteriorate at any time during the study. In contrast, the systolic time intervals $\left(\mathrm{QS}_{2} \mathrm{I}, \mathrm{LVETI}\right.$, and PEPI) were all significantly higher at the time of deterioration than at entry into the study, and also, in the cases of $\mathrm{QS}_{2} \mathrm{I}$ and LVETI, than at the times of reintroduction of digoxin. However, the ratio PEP:LVET did not change during deterioration. Note that the values taken during the eighth week of placebo in those patients who deteriorated relate to patients whose clinical deterioration had, in most cases, been ameliorated by increases in dosages of diuretics.

An analysis of this kind including all those who deteriorated at any time during the study showed exactly the same patterns of change as shown by those who deteriorated while on placebo.

\section{ECHOCARDIOGRAPHY}

Figure 4 shows the changes in left ventricular internal diameter sizes during diastole $\left(\right.$ LVID $\left._{\mathrm{d}}\right)$ and during systole ( LVID $_{a}$ ) and the derived measures of ventricular contractility (fractional shortening and mean velocity of circumferential fibre shortening (VCF)) during the study. There were no changes in any of these echocardiographic measurements. In contrast with the systolic time intervals, however, we do not have any echocardiographic measurements in deteriorators at the time of deterioration.

\section{EXERCISE HEART RATES}

There were no changes in either resting heart rates just before exercise or peak heart rates during exercise, after either the withdrawal or the reintroduction of digoxin in any of the patients (data not illustrated).

\section{PHARMACOLOGICAL MEASUREMENTS}

Figure 5 shows the results of the erythrocytic specific binding of $\left[{ }^{3} \mathrm{H}\right]$-digoxin and uptake of rubidium-86. In those who did not deteriorate during digoxin withdrawal there was no change in either $\left[{ }^{3} \mathbf{H}\right]-$ digoxin binding or uptake of rubidium-86 during the eight weeks after withdrawal. One week after the reintroduction of digoxin, however, both $\left[{ }^{3} \mathrm{H}\right]-$ digoxin binding and uptake of rubidium-86 fell (consistent with occupation of erythrocytic sodium/ potassium pump sites and inhibition of ion transport) and then rose again after eight weeks of continuous treatment (consistent with pharmacological tolerance to the effects of digoxin, as we have described before $\left.{ }^{11}\right)$. In contrast, in those who did deteriorate after digoxin withdrawal this pattern of changes was reversed. After one week of withdrawal there was an increase in both the number of binding sites and the rate of rubidium-86 transport, consis-

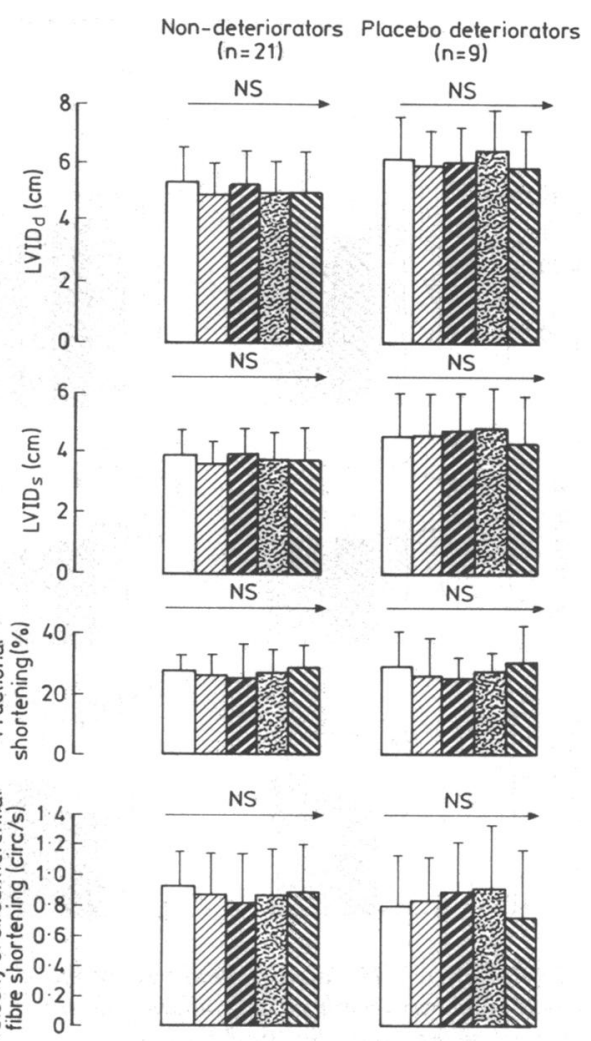

Fig 4 Echocardiographic LVID, LVID, fractional shortening, and VCF at different times of the study. See fig 3 for key.

tent with rebound from the effects of digoxin, and after eight weeks these had both returned to the values found before withdrawal. After the reintroduction of digoxin there were no changes in either binding or uptake.

Figure 5 shows the changes in intraerythrocytic sodium concentration during the withdrawal and reintroduction of digoxin. In those who did not deteriorate there was no change in intraerythrocytic sodium concentrations after digoxin withdrawal, but a significant increase after its reintroduction, an increase which persisted at eight weeks. In the deteriorators there was both a fall in intraerythrocytic sodium concentrations after the withdrawal of digoxin and an increase after its reintroduction.

Thus a comparison of deteriorators and nondeteriorators showed differences in the patterns of change in all three pharmacological measurements after the withdrawal and reintroduction of digoxin.

\section{Discussion}

We know of five previous randomised, double blind, 


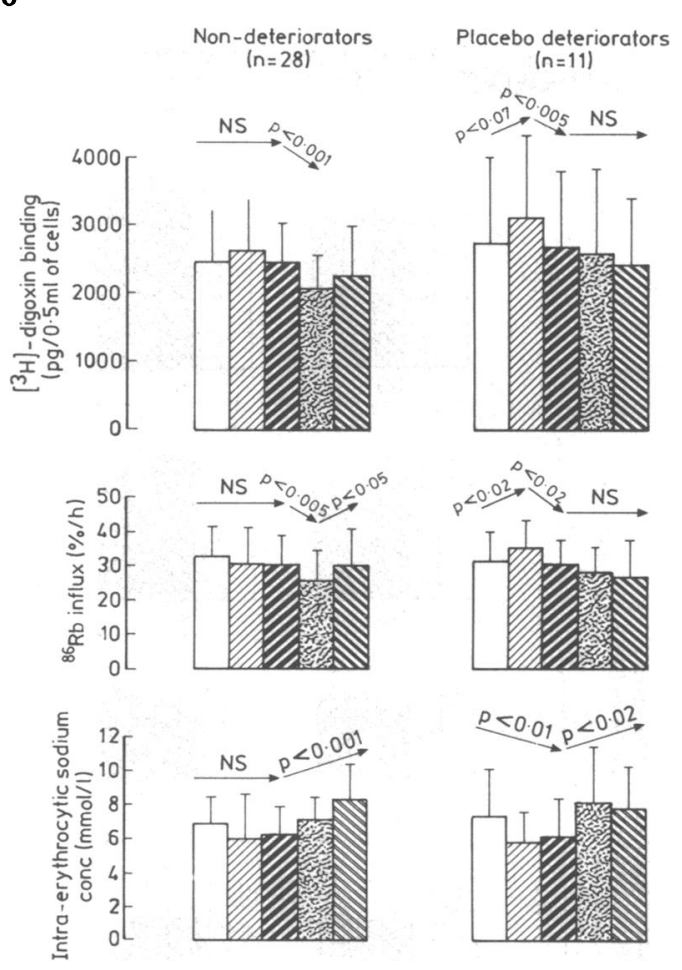

Fig 5 Erythrocytic $\left[{ }^{3} \mathrm{H}\right]$-digoxin binding, uptake of rubidium-86, and intraerythrocytic sodium concentrations at different times of the study. See fig 3 for key.

placebo controlled, crossover comparisons of digoxin with placebo after long term treatment for heart failure..$^{710^{1617}}$ In none of those was there a simultaneous comparison of the changes in the clinical, haemodynamic, and pharmacological effects of digoxin after its withdrawal. Nor was there a systematic comparison of the differences in changes in such effects between those who showed clinical deterioration after withdrawal and those who did not. We therefore compared haemodynamic and pharmacological changes after the withdrawal of digoxin with the clinical consequences of withdrawal, and in particular we compared those patients in whom withdrawal resulted in clinical deterioration with those in whom it did not.

\section{OCCURRENCE OF CLINICAL DETERIORATION DURING THE STUDY}

To determine the occurrence of deterioration during the period of study we used a scoring system similar to those previously used by others, ${ }^{71017}$ and designed to detect changes in both signs and symptoms. We defined deterioration quite stringently, requiring a
Pugh, White, Aronson, Grahame-Smith, Bloomfield consistent increase in total score of at least two points, and a worsening of at least one sign of cardiact failure. In those whom we considered not to have: deteriorated clinically (a judgement that was reached before the analysis of the other data), though there were occasional increases of one or two points in the scores relating to symptoms, these were not consis tently present during the relevant study period, and required no changes in treatment.

The results show firstly that by these criteria mos patients $(64 \%)$ did not have evidence of clinica $\vec{P}$ deterioration during the study, and secondly that $\vec{t}$ when deterioration occurred it did so in some casem $(11 \%)$ despite the continuing presence of digoxin. In? only $25 \%$ of patients did clinical deterioration occubs after digoxin withdrawal. Even then we found $i \vec{b}$ possible to control worsening heart failure simply bie increasing the dose of diuretics, and in only twoo patients $(5 \%)$ did we find that cardiac failure did nog resolve until digoxin was reintroduced. In two other patients digoxin was required to control fast atriat fibrillation which occurred during placebo treat ment.

Thus although the proportion of patients deteriorating during our study (36\%) was similar to that previously found by others, ${ }^{23}$ in only $25 \%$ of cases was deterioration directly attributable to a los of the beneficial effect of digoxin rather than t $\bar{d}$ deterioration caused by the natural course of cardia $\frac{2}{8}$ failure, and in only four cases $(9 \%)$ was reintroduc $\frac{\mathrm{O}}{2}$ tion of digoxin necessary.

Two of the four patients who developed atria? fibrillation during the study did so while taking digoxin (plasma digoxin concentrations 1.6 and 1.3 . $\mathrm{ng} / \mathrm{ml}$ ). This is consistent with the widespread belief that digoxin may not be useful in preventing atriat fibrillation (for example in paroxysmal atrial fibrilla tion).

\section{HAEMODYNAMIC CHANGES AFTER DIGOXIN} WITHDRAWAL AND REINTRODUCTION

The changes in systolic time intervals at the time of onset of clinical deterioration while on placebo (fig $3 \frac{2}{2}$. left hand panel) are consistent both with worsening of cardiac failure because of reduced left ventricula? contractility (as assessed by a prolongation of the leff ventricular ejection time) and with the loss of the usual effects of digoxin on cardiac conduction (reflec ted in a lengthening of total electromechanical syse tole) not entirely attributable to the lengthening of the ventricular ejection time. One would have expec.ted the ratio of pre-ejection period (PEP) to the lefp ventricular ejection time (LVET) to have decrease $\$$ with worsening heart failure because of the lengthene ing of the LVET, but because of the concomitant los $\$$ of the effect of digoxin on the PEP, albeit a smalat 
effect, there was no significant change in PEP:LVET. This is consistent with our previous observations that although total electromechanical systole and LVETI shorten significantly when heart failure responds to treatment with digoxin, the ratio of PEP:LVET does not alter. ${ }^{14}$

By the end of the eighth week of placebo treatment in these patients, who had deteriorated after withdrawal of digoxin, there was clinical improvement in cardiac function caused by the administration of increased dosages of diuretics, and in consequence the LVETI once again shortened (fig 3, right hand panel). This is also consistent with the lack of overall change in echocardiographic measurements over the same period of time. None the less, at that time there was still significant lengthening of the $Q S_{2} I$ and PEPI, indicative of the continuing absence of the effects of digoxin. In the patients who had not deteriorated (fig 3, middle panel) there was no change in myocardial contractility, as assessed by the LVETI and echocardiographic measurements, but there was none the less evidence of a loss of the effects of digoxin, as assessed by increases in $Q_{2} I$ and PEPI. These changes were smaller than the changes seen in the patients who deteriorated while on placebo, but nevertheless they suggest that digoxin was exerting a pharmacodynamic effect on the heart that was not contributing to the control of heart failure in these patients, and which could therefore be lost after withdrawal without consequent deterioration of the patients' clinical state.

After the reintroduction of digoxin the systolic time intervals $\mathrm{QS}_{2} I$ and PEPI shortened in both groups, showing that the heart was still responsive to the electrophysiological effects of digoxin. In contrast, there was no overall change in LVETI or PEP/ LVET in either group. This suggests that in patients in whom diuretic treatment has been successful in relieving the signs and symptoms of heart failure, digitalis has little to offer in the way of additional positive inotropic support. In patients who deteriorated, the fall in LVETI from the time of deterioration to the time of reintroduction of digoxin may be attributable to improvement in left ventricular function secondary to increases in diuretic dosages.

\section{CHANGES IN EXERCISE TESTING DURING} WITHDRA WAL

We were unable to carry out exercise testing at every visit, and therefore could not detect any changes in exercise capacity or peak heart rate during exercise at times of deterioration. By the eighth week of placebo treatment the exercise responses were unchanged, even in those who had previously deteriorated clinically, presumably because of the increases in diuretic dosages. This observation is consistent with the finding of others that digoxin does not improve exercise tolerance in patients in whom diuretics have been used to produce a stable body weight. ${ }^{18}$

\section{CHANGES IN PHARMACOLOGICAL}

MEASUREMENTS DURING WITHDRAWAL AND

REINTRODUCTION OF DIGOXIN

There are clearly differences in the patterns of change during withdrawal and reintroduction of digoxin when those who deteriorated are compared with those who did not. Two features of these patterns are particularly noteworthy.

Firstly, in those who deteriorated, but not in those who did not, withdrawal of digoxin was associated with a rebound in both $\left[{ }^{3} \mathrm{H}\right]$-digoxin binding and uptake of rubidium-86, both of which rose at one week after withdrawal and then returned to prewithdrawal values after eight weeks. This suggests that in those who deteriorated the effects of digoxin in occupying sodium/potassium pump sites, and thus in inhibiting transport, were lost during withdrawal. This was accompanied at one week by a fall in intraerythrocytic sodium concentration. If that also happened in the heart it could have been responsible for the loss of therapeutic effect seen in these patients, by causing secondary changes in calcium disposition in the opposite direction from the changes that have been postulated to occur as part of the positive inotropic action of digitalis. ${ }^{19}$

Secondly, after the reintroduction of digoxin in the non-deteriorators, but not in the deteriorators, there was a fall in binding and uptake and at eight weeks a return to the values found before reintroduction. This shows that the sodium/potassium pump sites in the erythrocytes of these patients were still capable of both responding to the pharmacological effects of digoxin and of adapting to those effects, as we have previously shown. ${ }^{11}$

It is not clear to us why rebound after withdrawal did not occur in those who did not deteriorate nor why there was no evidence of a pharmacological effect on the erythrocytes after reintroduction in those who did deteriorate. It may be that there is a difference in the time course of effects in the two groups, and that we have failed to detect changes because we took samples only at one and eight weeks. Alternatively, it may be that other mechanisms participate in the control of the numbers and activity of $\mathrm{Na} / \mathrm{K}$-ATPase sites on the erythrocyte membrane, and that these differ in deteriorators and nondeteriorators. For example, an endogenous inhibitor of the sodium/potassium pump, with a different rate of turnover in the two groups, could have produced differential results. The fact that the intraerythrocytic sodium concentrations showed different pat- 
terns of change from the two other pharmacological measurements suggests that other factors may have played a part.

\section{PREDICTION OF DETERIORATION BEFORE WITHDRAWAL}

It would clearly be of value to have a measurement or observation in patients on long term digoxin treatment that would help to predict whether or not deterioration might be expected after digoxin withdrawal. However, none of the measurements we made at the time of entering patients into the study proved of value in discriminating between those patients who subsequently deteriorated and those who did not (table 3 ). This finding is consistent with the findings of other workers who were unable to relate the outcome of withdrawal to any one of several measures, including age, sex, New York Heart Association class, the use of diuretics, the previous duration of digoxin treatment, the cause of the heart disease, and cardiac rhythm. ${ }^{710}$ In one study the presence of a third heart sound was found to be a good predictor of deterioration, ${ }^{16}$ presumably since it reflects relatively poor left ventricular contraction. None of our patients had a third heart sound at entry to the study and we cannot therefore make any conclusions about that. Patients with plasma digoxin concentrations below $0.8 \mathrm{ng} / \mathrm{ml}$ are very unlikely to deteriorate after digoxin withdrawal, ${ }^{40}$ but this could not have contributed to our results since we studied patients with plasma digoxin concentrations $\geqslant 0.8 \mathrm{ng} / \mathrm{ml}$ at entry to the study, and during digoxin treatment periods used dosages of digoxin which kept the plasma concentrations above $0.8 \mathrm{ng} / \mathrm{ml}$.

It is clear from the results of this and other studies that digoxin continues to exert a beneficial effect in some patients with heart failure in sinus rhythm.

There are, however, no clear-cut criteria to predict which patients will deteriorate after digoxin withdrawal. Nevertheless, it is possible to formulate guidelines for the use of digoxin in the long term management of heart failure in sinus rhythm:

(a) If a patient is in a stable condition and has a plasma digoxin concentration below $0.8 \mathrm{ng} / \mathrm{ml}$ digoxin withdrawal is very likely to be safe. It has been suggested by others that this applies to patients not only in sinus rhythm but also in atrial fibrillation. 420

(b) If a patient is in a stable condition, has a plasma digoxin concentration $\geqslant 0.8 \mathrm{ng} / \mathrm{ml}$, and is not at great risk of toxicity, digoxin withdrawal is probably not worth while, because there is a $25 \%$ risk of deterioration.

(c) If, however, there is an increased risk of digitalis toxicity (for example in a patient with deteriorating renal function, or in one who has difficulty in
Pugh, White, Aronson, Grahame-Smith, Btoomfield $\stackrel{\text { " }}{\underset{T}{\square}}$ maintaining potassium balance) then careful with $-\frac{1}{\mathbb{D}}$ drawal may be worth attempting.

(d) In a few patients (for example those with a third heart sound) it may be better to continue treatment, $\stackrel{\vec{\rho}}{\longrightarrow}$ even when there is an increased risk of digitaliso toxicity. In that case, however, monitoring of treat-을 ment should be increased to reduce the risk of $\frac{\bar{w}}{\frac{5}{}}$ toxicity.

Throughout this discussion we have assumed that: digoxin treatment was thought to be appropriate in the first place, either alone or in addition to diuretics,, vasodilators, or angiotensin converting enzyme $\vec{\omega}$ inhibitors. As alternative forms of treatment become available the role of digitalis in the long term management of cardiac failure will undoubtedlyo evolve further.

SEP and JKA acknowledge the support of the Wellcome Trust. Additional financial support was given by the Oxfordshire Regional Health Authority.The Wellcome Foundation Ltd kindly supplied dummy tablets to match Lanoxin.

\section{References}

1 Withering W. An account of the foxglove and some of its medical uses: with practical remarks on dropsy and othern diseases. Paternoster-Row, London: G G J and J®ి Robinson, 1785.

2 Aronson JK. Cardiac glycosides and drugs used inō dysrhythmias. In: Dukes MNG, ed. Side effects of 3 drugs, annual 4. Amsterdam: Excerpta Medica, 1980:122-6.

3 Fleg JL, Lakatta EG. How useful is digitalis in patients with congestive heart failure and sinus rhythm? Int $\mathbb{D}^{\mathbb{D}}$ Cardiol 1984;6:295-305.

4 Johnston GD, McDevitt DG. Is maintenance digoxin' necessary in patients with sinus rhythm? Lancet 1979;1:567-70.

5 Sommers DeK, Reitz CJ, Koch K, Avenant JC Digoxin withdrawal in patients with sinus rhythm. So Afr Med J 1981;60:239-40.

6 Gheorghiade M, Beller G. Effects of discontinuing maintenance digoxin therapy in patients with is chemic heart disease and congestive heart failure in sinus rhythm. Am J Cardiol 1983;51:1243-50.

7 Dobbs SM, Kenyon WI, Dobbs RJ. Maintenance digoxin after an episode of heart failure: placebo- $\omega$ controlled trial in outpatients. $\mathrm{Br} M e d J 1977 ; 1: 749-0$ 52.

8 Griffiths BE, Penny WJ, Lewis $M J$, Henderson $A H \stackrel{\odot}{\odot}$ Maintenance of the inotropic effect of digoxin on? long-term treatment. Br Med J 1982;284:1819-22. T

9 Fleg JL, Gottlieb SH, Lakatta EG. Is digoxin reallyo important in treatment of compensated heart failure? A placebo-controlled crossover study in patients with sinus rhythm. Am J Med 1982;73:244-50.

10 Taggart AJ, Johnston GD, McDevitt DG. Digoxit 
withdrawal after cardiac failure in patients with sinus rhythm. J Cardiovasc Pharmacol 1983;5:229-34.

11 Aronson JK, Ford AR, Grahame-Smith DG. Techniques for studying the pharmacodynamic effects of cardiac glycosides on patients' own erythrocytes during glycoside therapy. Klin Wochenschr 1981; 59:1323-32.

12 Cumberbatch M, Zareian K, Davidson C, Morgan DB, Swaminathan $R$. The early and late effects of digoxin treatment on the sodium transport, sodium content and $\mathrm{Na}^{+} \mathrm{K}^{+}$-ATPase of erythrocytes. Br J Clin Pharmacol 1981;11:565-70.

13 Weissler AM, Lewis RP, Leighton RF. The systolic time intervals as a measure of left ventricular performance in man. In: Progress in cardiology. Philadelphia: Lea and Febiger, 1972;vol 1:155-83.

14 Ford AR, Aronson JK, Grahame-Smith DG, Carver JG. Changes in cardiac glycoside receptor sites, ${ }^{86}$ rubidium uptake and intracellular sodium concentrations in the erythrocytes of patients receiving digoxin during the early phases of treatment of cardiac failure in regular rhythm and of atrial fibrillation. Br J Clin Pharmacol 1979;8:125-34.

15 Aronson JK, Grahame-Smith DG, Hallis KF, Hibble A, Wigley F. Monitoring digoxin therapy: I. Plasma concentrations and an in vitro assay of tissue response. Br J Clin Pharmacol 1977;4:213-21.

16 Lee DC-S, Johnson RA, Bingham JB, et al. Heart failure in outpatients. A randomized trial of digoxin versus placebo. N Engl J Med 1982;306:699-705.

17 Boman K. Digoxin and the geriatric in-patient. A randomized trial of digoxin versus placebo. Acta Med Scand 1983;214:353-60.

18 McHaffie D, Purcell H, Mitchell-Heggs P, Guz A. The clinical value of digoxin in patients with heart failure and sinus rhythm. $Q J$ Med 1978;NS48:401-19.

19 Noble D. Mechanism of action of therapeutic levels of cardiac glycosides. Cardiovasc Res 1980;14:495-514.

20 Liverpool Therapeutics Group. Use of digitalis in general practice. Br Med J 1978;ii:673-5. 